\title{
Ultra-Lightweight EPS Concrete: Mixing Procedure and Predictive Models for Compressive Strength
}

\author{
Fayez Moutassem \\ Department of Civil and Infrastructure Engineering, American University of Ras Al Khaimah, United Arab Emirates
}

Received July 23, 2020; Revised August 31, 2020; Accepted September 29, 2020

\section{Cite This Paper in the following Citation Styles}

(a): [1] Fayez Moutassem, "Ultra-Lightweight EPS Concrete: Mixing Procedure and Predictive Models for Compressive Strength," Civil Engineering and Architecture, Vol. 8, No. 5, pp. 963 - 972, 2020. DOI: 10.13189/cea.2020.080523.

(b): Fayez Moutassem (2020). Ultra-Lightweight EPS Concrete: Mixing Procedure and Predictive Models for Compressive Strength. Civil Engineering and Architecture, 8(5), 963 - 972. DOI: 10.13189/cea.2020.080523.

Copyright $\odot 2020$ by authors, all rights reserved. Authors agree that this article remains permanently open access under the terms of the Creative Commons Attribution License 4.0 International License

\begin{abstract}
Expanded polystyrene (EPS) lightweight concrete is increasingly used in various applications due to its lightweight, excellent heat preservation, sound insulation and energy absorbing characteristics. However, due to the hydrophobic nature and very low density of EPS beads, EPS concretes are prone to segregation, poor bonding, and homogeneity issues. The properties of EPS concrete are highly dependent on the mixture proportions and mixing procedure. This study involves the development of a quality mixing procedure for Ultra-lightweight EPS concrete and the development of two predictive compressive strength models function of concrete mixture and density, respectively. An experimental program is developed to implement the mixing procedure and to calibrate and evaluate the accuracy of the models. The proposed models were found to accurately predict the strength of concrete mixtures. The corresponding standard error for the models is less than 0.3 $\mathrm{MPa}$ and the corresponding correlation coefficient is greater than 0.93 . To ensure quality control before concrete is cast, a link between the plastic density of fresh concrete and the compressive strength was established. Furthermore, to accommodate tight construction schedules, the effects of concrete age on the compressive strength development were studied and the 28-day strength was related to strengths at early ages.
\end{abstract}

Keywords EPS Concrete, Lightweight Concrete, Foamed Concrete, Expanded Polystyrene, Compressive Strength, Density, Mixture Proportioning, Mixing Procedure

\section{Introduction}

There is a growing interest in using alternative sustainable and economical materials. Expanded polystyrene (EPS) is normally used as a packaging material due to its low density, hydrophobic properties, good thermal insulation, low absorption, and low cost. The yearly global production of polystyrene is over fourteen million tons and a very significant quantity of EPS ends up as waste materials that are sent to landfills, which are of limited space [1,2]. EPS concrete is increasingly being used in various applications in the construction industry and other industries mainly due to its lightweight, excellent heat preservation and sound insulation [1,3]. It can be used as base coarse materials for pavements, construction materials for cladding panels, lightweight partition walls, floating marine structures, sea beds, an energy-absorbing material for protection of buried military structures, and fenders for offshore oil platforms $[4,5,6,7,8]$. Ultra-lightweight EPS concrete is produced by fully replacing the normal aggregates (fine and coarse) with EPS beads and using other materials/admixtures to ensure proper bonding, high flowability, good stability and good surface finish.

The hydrophobic nature and very low-density of EPS beads can be a disadvantage when used in concrete because EPS concrete will be prone to segregation and poor bonding in comparison with normal weight concretes [9]. The significantly lower stiffness of the EPS aggregates in comparison with the cement paste will cause varying stress distributions inside the concrete. In addition, there is a difference between the failure pattern and the interfacial 
transition zone (ITZ) for EPS concrete in comparison with normal weight concrete. Unlike EPS concrete, failure of normal weight concretes occurs around the aggregate particles because the tensile strength of aggregates is higher than that of the surrounding cement paste [2]. Because of the low bond between the EPS and the cement paste, and hydrophobic nature and low mechanical strength of EPS beads, there is a significant decrease in the compressive strength of EPS concretes [7,10,11]. The properties of EPS concrete are highly dependent on the mixture proportions and mixing procedure. Therefore, understanding the behavior of fresh EPS concrete and following a proper mixing process can significantly improve its quality, homogeneity, stability, and avoid segregation. Furthermore, adding silica fume as a cement replacement provides mixtures that are more cohesive and less prone to segregation [12].

Research studies have shown that the density of EPS concrete significantly affects its compressive strength and that compressive strength is more sensitive to the density compared to tensile strength and modulus of elasticity [13]. Multiple previous studies have shown that the density of lightweight concrete is the most significant property influencing its compressive strength where an increase in density results in a higher compressive strength $[7,14,15,16]$. Research has shown that the compressive strength of EPS concrete increases with a decrease in EPS bead size, for the same concrete density. However, for lower EPS concrete densities, it was observed that EPS bead size's influence on the lightweight concrete compressive strength becomes negligible [17].

Therefore, based on previous studies, there is a further need to minimize the lack of homogeneity and stability issues encountered through proper mixture proportioning and mixing design process. Since the EPS concrete behavior and failure pattern are different from normal concretes, the models developed to predict the compressive strength of normal concretes should not be used and specific models should be developed for EPS concrete. Accurate prediction of the compressive strength of EPS concrete before concrete is cast is needed for appropriate design of EPS concrete mixtures and for quality control purposes. This study involves the development of a quality mixing procedure for EPS concrete and the development of two predictive compressive strength models function of concrete mixture and density, respectively. An experimental program is developed to implement the mixing procedure and to calibrate and evaluate the accuracy of the strength models. Furthermore, to ensure quality control before concrete is cast, a link between the plastic density of fresh concrete and the compressive strength of hardened concrete needs to be stablished.

\section{Experimental Program}

\subsection{Materials}

This section presents the details for all materials used in concrete mixtures including their technical properties. A total 30 mixtures were fabricated. ASTM Type I ordinary Portland cement (OPC) was used for all concrete mixtures. The chemical and physical properties of the cement are summarized in Table 1. Condensed silica fume (ELKEM 920D) with a 28-day compressive strength of $56 \mathrm{MPa}$ and meeting the ASTM requirements was used as cement replacement for 11 mixtures. Commercially available Grey colored spherical EPS beads (NEOPOR F 5300- BASF) as shown in Figure 1 were used for all mixtures. EPS beads size was $2.5-3.5 \mathrm{~mm}$ and bulk density was $15-20 \mathrm{~kg} / \mathrm{m}^{3}$. Polycarboxilate-based High-Range Water Reducers (HRWR) were used to produce highly flowable concrete mixtures. A foaming admixture (FA) was used for 24 mixtures and an air-entraining admixture (AA) was used for 6 mixtures. A latex-based bonding agent (Planicrete SP- MAPEI) was used for all mixtures to improve the bonding between EPS beads and the paste.

Table 1. Chemical and Physical Properties of OPC

\begin{tabular}{cc}
\hline Properties & \% of Weight \\
\hline $\mathrm{SiO}_{2}(\%)$ & 19.5 \\
$\mathrm{Al}_{2} \mathrm{O}_{3}(\%)$ & 4.69 \\
$\mathrm{Fe}_{2} \mathrm{O}_{3}(\%)$ & 3.70 \\
$\mathrm{CaO}(\%)$ & 63.3 \\
$\mathrm{MgO}(\%)$ & 1.46 \\
$\mathrm{SO}_{3}(\%)$ & 2.58 \\
Loss on Ignition (\%) & 3.59 \\
Equivalent Alkalies (\%) & 0.54 \\
Specific Surface Area (Blaine) (m²/kg) & 345 \\
Soundness, Expansion (mm) & 1.10 \\
Time of Setting-Initial (min) & 160 \\
Compressive Strength - 28 Days (MPa) & 47.6 \\
\hline
\end{tabular}

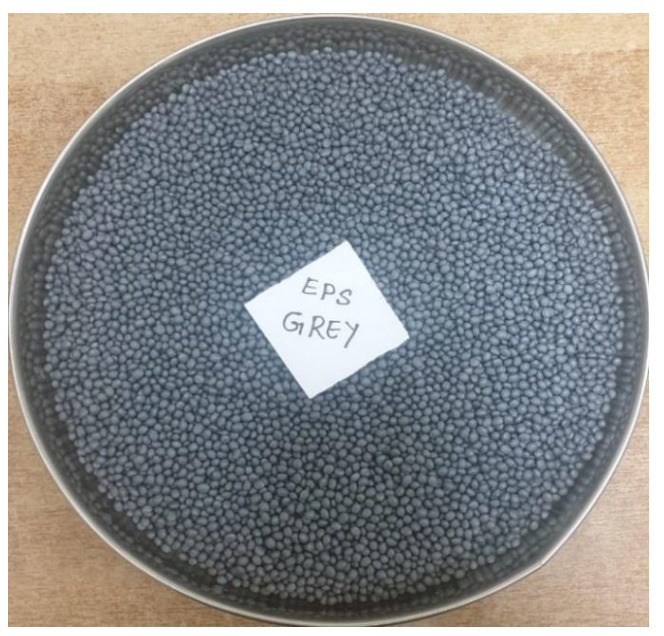

Figure 1. EPS Beads (NEOPOR F 5300) - Grey Color 
Table 2. Concrete Mixture Design Composition

\begin{tabular}{|c|c|c|c|c|c|c|c|}
\hline Mix \# & w/c & $\operatorname{EPS}\left(\mathrm{kg} / \mathrm{m}^{3}\right)$ & OPC $\left(\mathrm{kg} / \mathrm{m}^{3}\right)$ & $\mathrm{SF}\left(\mathrm{kg} / \mathrm{m}^{3}\right)$ & $\begin{array}{c}\text { High-Range Water } \\
\text { Reducer }\left(\mathrm{kg} / \mathrm{m}^{3}\right)\end{array}$ & $\begin{array}{l}\text { Air Agent } \\
\left(\mathrm{kg} / \mathrm{m}^{3}\right)\end{array}$ & Type \\
\hline 1 & 0.24 & 13.8 & 744 & 0 & 4.10 & 0.0 & - \\
\hline 2 & 0.25 & 14.0 & 550 & 0 & 9.60 & 3.0 & AA \\
\hline 3 & 0.30 & 14.0 & 500 & 0 & 5.80 & 3.1 & FA \\
\hline 4 & 0.30 & 14.0 & 500 & 0 & 4.15 & 2.1 & FA \\
\hline 5 & 0.30 & 14.0 & 500 & 0 & 6.00 & 2.0 & FA \\
\hline 6 & 0.30 & 14.0 & 500 & 0 & 5.80 & 3.1 & FA \\
\hline 7 & 0.30 & 14.0 & 450 & 0 & 3.05 & 3.0 & FA \\
\hline 8 & 0.33 & 15.2 & 400 & 0 & 1.52 & 3.5 & FA \\
\hline 9 & 0.30 & 14.8 & 450 & 0 & 2.65 & 3.5 & FA \\
\hline 10 & 0.30 & 14.8 & 450 & 0 & 3.20 & 3.0 & FA \\
\hline 11 & 0.30 & 14.8 & 450 & 0 & 2.70 & 3.0 & FA \\
\hline 12 & 0.30 & 14.8 & 450 & 0 & 1.80 & 3.0 & FA \\
\hline 13 & 0.30 & 14.8 & 450 & 0 & 2.50 & 3.5 & FA \\
\hline 14 & 0.30 & 13.9 & 430 & 0 & 2.50 & 3.3 & FA \\
\hline 15 & 0.30 & 13.9 & 430 & 0 & 1.50 & 3.3 & FA \\
\hline 16 & 0.30 & 13.9 & 430 & 0 & 1.25 & 3.3 & FA \\
\hline 17 & 0.30 & 13.9 & 430 & 0 & 1.25 & 3.3 & FA \\
\hline 18 & 0.30 & 13.9 & 430 & 0 & 3.15 & 8.8 & AA \\
\hline 19 & 0.30 & 13.7 & 407 & 23 & 5.90 & 7.0 & AA \\
\hline 20 & 0.30 & 13.8 & 407 & 23 & 1.75 & 7.0 & AA \\
\hline 21 & 0.30 & 13.7 & 407 & 23 & 5.00 & 3.0 & FA \\
\hline 22 & 0.30 & 13.8 & 407 & 23 & 2.18 & 3.5 & FA \\
\hline 23 & 0.28 & 14.0 & 407 & 23 & 2.00 & 7.0 & AA \\
\hline 24 & 0.30 & 13.8 & 407 & 23 & 1.98 & 7.0 & $\mathrm{AA}$ \\
\hline 25 & 0.30 & 13.8 & 407 & 23 & 2.18 & 3.0 & FA \\
\hline 26 & 0.30 & 13.8 & 407 & 23 & 2.18 & 3.5 & FA \\
\hline 27 & 0.30 & 13.8 & 407 & 23 & 2.15 & 2.5 & FA \\
\hline 28 & 0.30 & 13.8 & 407 & 23 & 2.13 & 2.0 & FA \\
\hline 29 & 0.32 & 14.9 & 350 & 0 & 2.20 & 1.5 & FA \\
\hline 30 & 0.32 & 13.5 & 325 & 30 & 2.20 & 1.5 & FA \\
\hline
\end{tabular}

\subsection{Mixture Proportions}

The design variables used in proportioning the concrete mixtures include the water-to-cementing materials ratio, cementing materials content, which includes OPC and Silica Fume, amount of EPS beads, amount of air entrainment, and amount of HRWR. The range selected for $\mathrm{w} / \mathrm{c}$ was from 0.24 to 0.33 . The water content values ranged from 112 to $179 \mathrm{~kg} / \mathrm{m}^{3}$. The cementing materials content ranged from 350 to $744 \mathrm{~kg} / \mathrm{m}^{3}$. Amount of EPS beads ranged from 13.5 to $15.3 \mathrm{~kg} / \mathrm{m}^{3}$ (56 to $63 \%$ by volume). The amount of bonding agent was $4 \mathrm{~kg} / \mathrm{m}^{3}$ for all mixes. Amounts of air entrainment and superplasticizers were varied to produce highly flowable low-density mixtures. Corresponding proportions for the 30 mixtures are given in Table 2.

\subsection{Proposed Mixing Procedure}

Mixing was performed in a horizontal pan mixer in the 
laboratory. It is well known that EPS concrete is prone to segregation mainly because of the EPS beads, which are very low in density and high in volume fraction. Accordingly, in this study, the ideal mixing process and sequence was investigated and varied in order to produce high quality homogeneous mixtures and avoid segregation.

The proposed mixing procedure is as follows:

1. Add the EPS beads to the mixer

2. Add the bonding agent to $1 / 3$ of the water and mix them together.

3. Pour it into the mixer and mix for 3 minutes. Note that wetting of the EPS beads with part of the mixing water and bonding agent is essential to ensure proper bonding with the rest of the materials and because the interfacial zone between cement paste and the EPS beads play a critical role in determining mechanical properties of concrete.

4. Pour the cementing materials and mix for 4 minutes

5. Add the foaming agent or air entrainer to the remaining water and mix them thoroughly for 1 minute.

6. Slowly pour it into to the mixer and mix for 2 minutes.

7. Add water reducer as needed to produce high workability and mix for 1.5 minutes.

8. Check the Slump. If the slump is as needed then proceed to concrete casting

\subsection{Casting, Curing and Testing}

Concrete casting, curing and testing was consistent for all of the concrete mixtures. The fresh concrete densities and slump values were measured immediately after mixing for all the concretes ASTM C138 and ASTM C143 respectively $[18,19]$. The concrete specimens were cast in steel molds, followed immediately by curing at room temperature for $24 \mathrm{~h}$ before being demolded. After demolding, the specimens were cured in lime-saturated water up to the date of testing. The density of hardened EPS concrete test was conducted in accordance with
ASTM C567 [20] at the age of 28 days. The compressive strength of hardened EPS concrete was measured on cube specimens (150 $\mathrm{mm} \times 150 \mathrm{~mm} \times 150 \mathrm{~mm})$ at the age of 1,7 and 28 days.

\subsection{Calibration and Validation Procedure}

The proposed models require determining of the calibration constants. Model Calibration was carried out by minimizing the standard error $(\sigma)$ between the model predictions and the measured experimental data. The standard error, which provides a global assessment of the model predictions, is defined in Equation 1 [21]:

$$
\sigma=\left\{\Sigma\left[f^{\prime} c_{m}(i)-f^{\prime} c_{\text {exp }}(i)\right]^{2} /(n-p)\right\}^{1 / 2}
$$

Where parameters $f^{\prime} c_{m}(i)$ and $f^{\prime} c_{\text {exp }}(i)$ refer to the model and experimental compressive strength values that correspond to mix $i$, respectively. Parameters $n$ and $p$ refer to the number of tested points and the number of model constants, respectively. This application provides an assessment of the goodness of fit and the soundness of the proposed model. In addition, the correlation coefficient $\left(R^{2}\right)$, which provides a measure of the proportion of model variability, was also calculated. Such measures permit assessment of the capabilities of the proposed model in predicting the trends reported in the literature.

\section{Results, Discussion, and Proposed Models}

\subsection{Experimental Testing Results}

Table 3 presents the experimental results for each mix, which includes values for the slump, air content, fresh density, hardened density, and compressive strength at 1, 7 and 28 days. The following sections will discuss the relevancy of the results obtained, and present and discuss the calibration and accuracy of the proposed compressive strength models. 
Table 3. Results of Experimental Testing

\begin{tabular}{|c|c|c|c|c|c|c|c|}
\hline Mix \# & Slump (mm) & $\begin{array}{l}\text { Air } \\
(\%)\end{array}$ & $\begin{array}{c}\text { Fresh Density } \\
\left(\mathrm{kg} / \mathrm{m}^{3}\right)\end{array}$ & $\begin{array}{c}\text { Hardened Density } \\
\left(\mathrm{kg} / \mathrm{m}^{3}\right)\end{array}$ & $\begin{array}{l}f^{\prime} c_{l d} \\
(\mathrm{MPa})\end{array}$ & $\begin{array}{l}f^{\prime} c_{7 d} \\
(\mathrm{MPa})\end{array}$ & $\begin{array}{l}f^{\prime} c_{28 d} \\
(\mathrm{MPa})\end{array}$ \\
\hline 1 & 70 & - & 978 & 996 & 4.32 & 7.05 & 7.79 \\
\hline 2 & 40 & 6 & 788 & 794 & 2.69 & 3.46 & 5.16 \\
\hline 3 & 150 & 11 & 764 & 759 & 1.93 & 3.58 & 3.99 \\
\hline 4 & 220 & 15 & 622 & 629 & 1.17 & 2.78 & 3.16 \\
\hline 5 & 240 & 11 & 669 & 646 & 1.64 & 2.35 & 3.45 \\
\hline 6 & 260 & 16 & 634 & 634 & 1.09 & 1.84 & 2.57 \\
\hline 7 & 230 & 13 & 679 & 691 & 1.52 & 3.05 & 3.78 \\
\hline 8 & 240 & 21 & 490 & 458 & 0.64 & 1.22 & 1.45 \\
\hline 9 & 245 & 16 & 541 & 533 & 0.96 & 1.72 & 2.20 \\
\hline 10 & 275 & 14 & 604 & 576 & 0.79 & 1.45 & 2.63 \\
\hline 11 & 265 & 25 & 503 & 478 & 0.88 & 1.71 & 1.65 \\
\hline 12 & 240 & 20 & 527 & 554 & 1.24 & 2.21 & 2.83 \\
\hline 13 & 240 & 20 & 560 & 480 & 0.94 & 1.88 & 2.26 \\
\hline 14 & 255 & 19 & 547 & 585 & 1.25 & 2.20 & 2.72 \\
\hline 15 & 260 & 17 & 551 & 521 & 1.12 & 1.98 & 2.08 \\
\hline 16 & 235 & 14 & 644 & 561 & 0.97 & 2.08 & 2.72 \\
\hline 17 & 245 & 15 & 664 & 555 & 1.03 & 1.87 & 2.52 \\
\hline 18 & 220 & 17 & 588 & 605 & 1.22 & 2.22 & 2.86 \\
\hline 19 & 230 & 13 & 669 & 595 & 1.40 & 2.78 & 2.82 \\
\hline 20 & 220 & 15 & 625 & 538 & 1.27 & 2.13 & 2.40 \\
\hline 21 & 220 & 11 & 661 & 706 & 1.46 & 2.77 & 3.51 \\
\hline 22 & 225 & 18 & 574 & 568 & 1.08 & 2.02 & 2.55 \\
\hline 23 & 230 & 10 & 706 & 691 & 1.77 & 2.76 & 3.31 \\
\hline 24 & 230 & 9 & 697 & 680 & 1.67 & 2.73 & 3.28 \\
\hline 25 & 225 & 17 & 580 & 608 & 1.00 & 2.54 & 2.57 \\
\hline 26 & 230 & 15 & 587 & 533 & 0.87 & 2.50 & 2.35 \\
\hline 27 & 245 & 20 & 509 & 509 & 1.07 & 1.62 & 2.21 \\
\hline 28 & 240 & 20 & 578 & 500 & 0.66 & 1.96 & 1.87 \\
\hline 29 & 240 & 18 & 528 & 478 & 0.52 & 1.32 & 1.75 \\
\hline 30 & 240 & 22 & 544 & 473 & 0.53 & 1.53 & 1.91 \\
\hline
\end{tabular}

\subsection{Workability and Surface Finish}

The workability of fresh concrete was evaluated in terms of the slump test. High workability was achieved for 28 mixtures to ensure ease of casting and placing. Mixtures 4 to 30 shown in Table 3 exhibited high flow characteristics with the slump values exceeding $220 \mathrm{~mm}$. Figure 2 demonstrates the slump test performed for a typical mix and shows the high workability, consistency and stability of the mixture. Good surface finish is very important for EPS concrete to ensure proper bonding with other materials especially if used as a core filling material such as for partition walls or other purposes. Figure 3 demonstrates the good surface finish of cast cubes for a typical mix. Good consistency, uniformity, stability and surface finish confirm the successful mix design and implementation of the proposed mixing procedure. 




Figure 2. Consistency of a Typical EPS Concrete Mix



Figure 3. Surface Finish for EPS Concrete Cubes

\subsection{Concrete Density}

Density is one of the important parameters which can control many physical properties in EPS concrete $[7,14,15]$. The density and compressive strength of EPS concrete are dominated by the porosity of specimen, which is mainly controlled by the volume fraction of air (entrapped and entrained), capillary porosity which depends on the water to cementing materials ratio, and the volume fraction of the EPS beads which are of negligible density and strength. Accordingly, density $(\rho)$ and compressive strength $\left(f_{c}^{\prime}\right)$ are related to the mixture proportions using the following relationship proposed in this study (Equation 2):

$$
\rho, f_{c}^{\prime} \propto(w+a+e p s) / c m
$$

Where $w, a$, eps and $\mathrm{cm}$ are the volume fractions of water, air, EPS, and cementing materials in the concrete mix. The experimental values for densities (fresh and hardened) ranging from 458 to $996 \mathrm{~kg} / \mathrm{m}^{3}$ are provided in Table 3 for each concrete mixture. Figure 4 shows the relationship between $(w+a+e p s) / \mathrm{cm}$ and the density of hardened concrete. As shown, an increase in the porosity results in a decrease in the density. An $R^{2}$ value of 0.86 confirms the high significance of this relationship on the density of concrete. Table 3 also shows that the fresh density exceeded the hardened density for 17 mixtures. Unlike the traditional concrete consisting of heavy aggregate, ultra-lightweight concrete consists of EPS aggregates with densities lower than the density of water. Any water not consumed during the hydration process would eventually evaporate leaving voids behind. The weight of the water lost may have a significant effect on the overall density of hardened ultra-lightweight concrete.

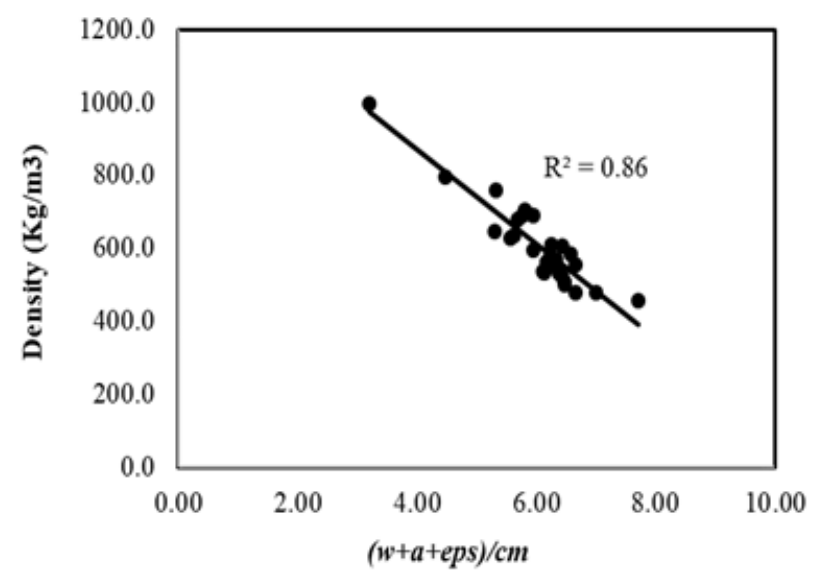

Figure 4. Relationship between Concrete Mixture and Density of Hardened Concrete

\subsection{Compressive Strength}

The 28-day compressive strength values $\left(f^{\prime} c_{28}\right)$ for the 30 concrete mixtures are given in Table 3 . For the 30 mixtures, the maximum and minimum compressive strength values are $7.79 \mathrm{MPa}$ and $1.45 \mathrm{MPa}$. Utilizing the dimensionless relationship presented in Equation 2 and applying statistical regression, it yields the following proposed fundamental model for predicting the compressive strength of lightweight EPS concrete as function of the mixture (Equation 3):

$$
f_{c}^{\prime}=A(B)^{(w+a+e p s) / c m}
$$

Where $A$ and $B$ are calibration constants. Calibration constant $A$ depends on the type and strength of cement and its unit is in $\mathrm{MPa}$ (or psi). Calibration constant $B$ is a dimensionless term, which depends on the specimen shape 
and the test conditions. The values of these calibration constants are given in Table 4. These constants were determined by minimizing the model standard error between the model predictions and measured experimental values. Figure 5 shows the goodness of fit of the proposed model (function of mixture) in comparison to the measured experimental data. The corresponding standard error and correlation coefficient were $0.30 \mathrm{MPa}$ and 0.93, respectively. The high degree of correlation and low standard error are evidence of the model's ability to predict the compressive strength of EPS concrete as a function of concrete mixture.

Multiple previous studies have shown that the density of light-weight concrete is the most significant property influencing its compressive strength $[7,14,15,16]$. Accordingly, the relationship between the density and compressive strength was investigated in this study. Using statistical regression, the following is the proposed fundamental model for predicting the compressive strength of lightweight EPS concrete as function of its hardened density (Equation 4):

$$
f_{c}{ }_{c}=A(B) \rho^{\prime 1000}
$$

Similarly, the calibration constant $A$ depends on the type and strength of cement and its unit is in $\mathrm{MPa}$ (or psi), and the calibration constant $B$, a dimensionless term, depends on the specimen shape and the test conditions. The values of these calibration constants are given in Table 4. Figure 6 shows the goodness of fit of the proposed model (function of density) in comparison to the measured experimental data. The corresponding standard error and correlation coefficient were $0.25 \mathrm{MPa}$ and 0.96 , respectively. The high degree of correlation and low standard error are evidence of the model's ability to predict the compressive strength of EPS concrete as a function of its hardened density.

In addition to the proposed predictive models, this study establishes a link between the plastic density of fresh concrete and the compressive strength of hardened concrete. This is important to ensure quality control before concrete is cast. Figure 7 presents this relationship and shows the goodness of fit. The corresponding correlation coefficient is 0.86 .

Table 4. Calibration of Proposed Compressive Strength

\begin{tabular}{ccccc}
\hline Models & $A$ & $B$ & $\sigma$ & $R^{2}$ \\
\hline $\begin{array}{c}\text { Compressive Strength } \\
\text { (Function of Mixture) }\end{array}$ & 25.8 & 0.69 & 0.30 & 0.93 \\
$\begin{array}{c}\text { Compressive Strength } \\
\text { (Function of Density) }\end{array}$ & 0.55 & 14.6 & 0.25 & 0.96 \\
\hline
\end{tabular}

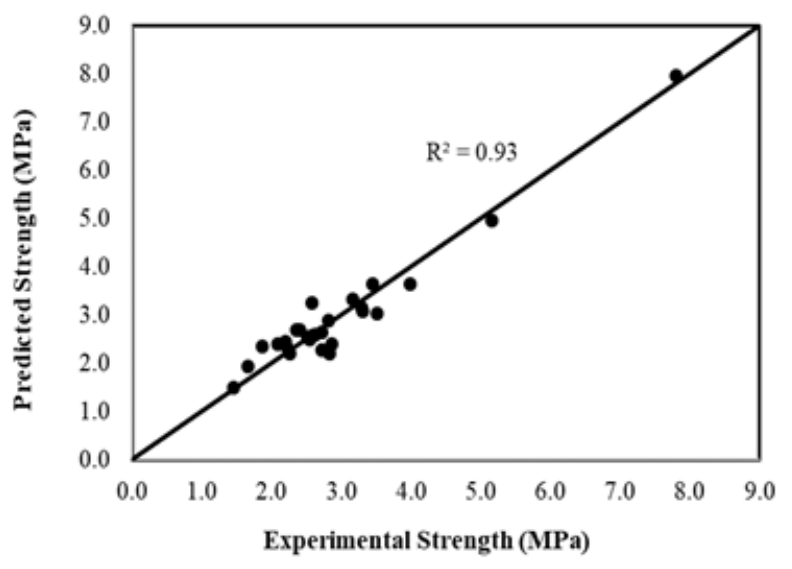

Figure 5. Compressive Strength Model (Function of Mixture) Vs. Experimental Values

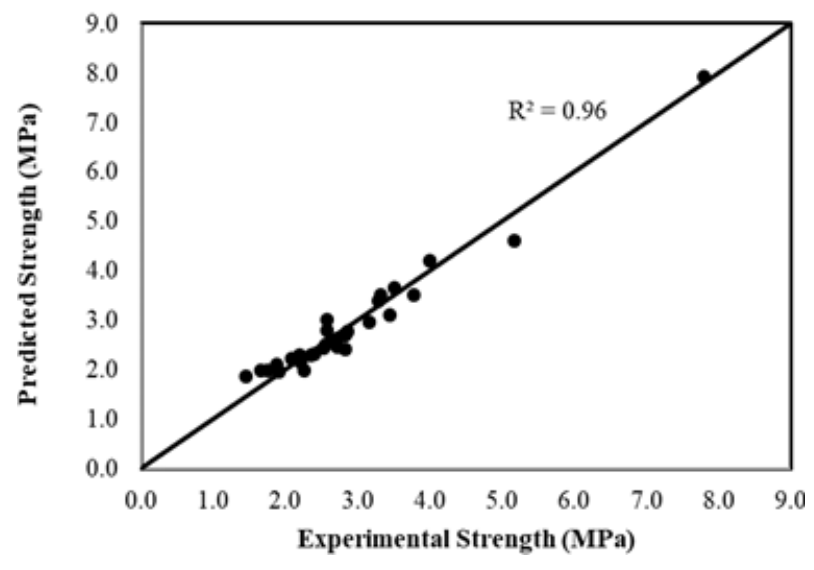

Figure 6. Compressive Strength Model (Function of Density) Vs. Experimental Values

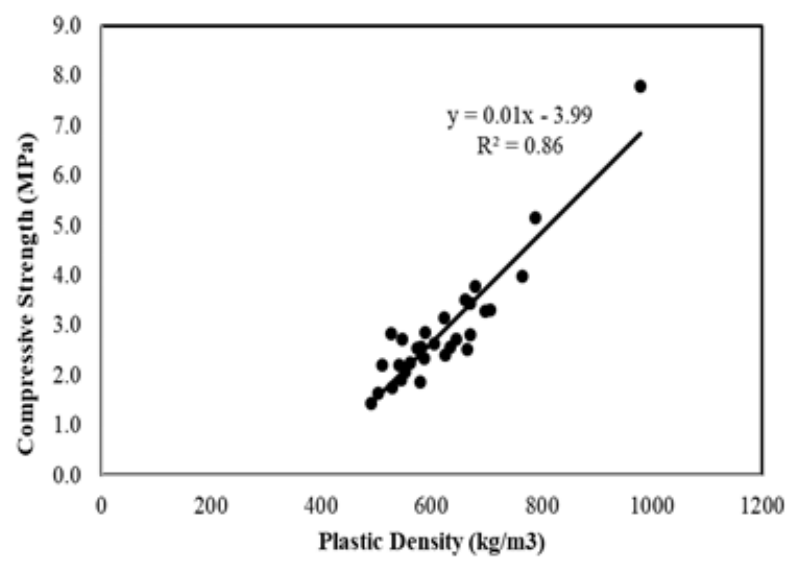

Figure 7. Relationship between Plastic Density and Compressive Strength 


\subsection{Rate of Strength Development and Concrete Age}

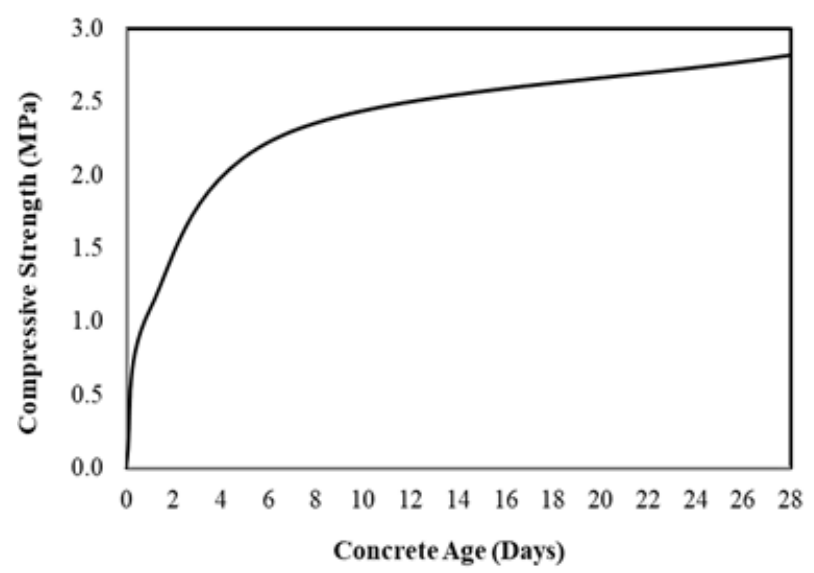

Figure 8. Rate of Strength Development

The effects of concrete age on the compressive strength development are illustrated in Figure 8. The rate of strength development was greater initially and decreased with time which is similar to traditional concretes. Based on the experimental results from this study, concrete develops around $48 \%$ of its 28 -day strength within 1-day, and $83 \%$ of its 28-day strength within 7 days. These results show that the rate of strength development for EPS concrete is higher than the traditional normal density concretes. It should be noted that 3 out of 30 mixtures (11, 26 and 28) resulted in 7-day strength slightly exceeding the 28-day strength. While this should not be the case, it may occur due to the high rate of strength development, low compressive strength values, and the sensitivity of ultra-lightweight concrete to casting and testing in comparison to normal concretes.

The proposed strength models (Eq. 2 and 3) were developed and calibrated for 28-day strength only because it is the main mix design requirement. However, the 28-day compressive strength can be related to strengths at early ages. This is important to accommodate tight construction schedules. Figure 9 shows the relationships between the 28-day compressive strength versus compressive strengths at 1-day and 7 days. The corresponding coefficients of correlation are 0.83 and 0.89 for the 1-day strength and 7-day strength, respectively.

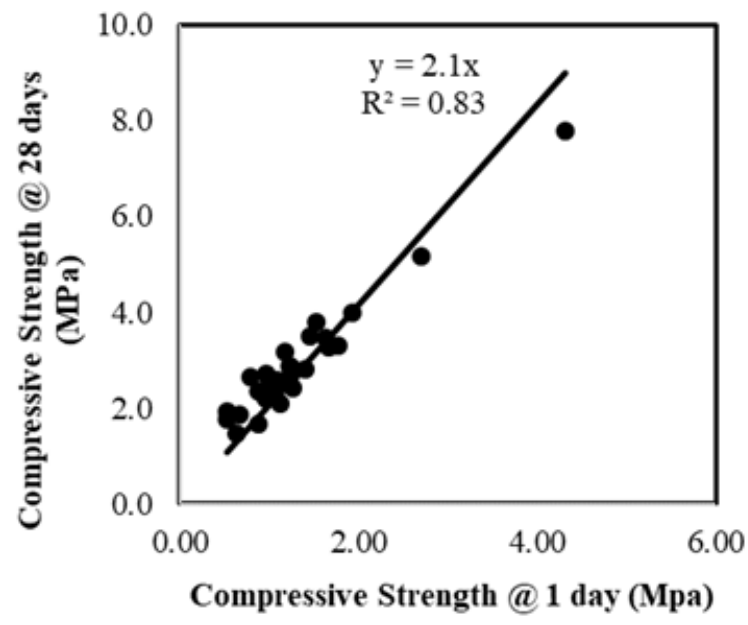

(a)

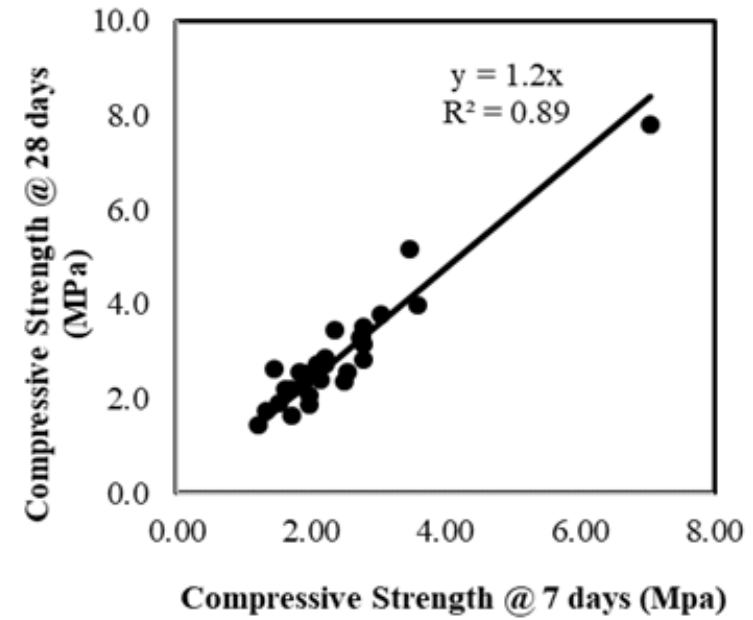

(b)

Figure 9. Relationships between Compressive Strengths at different Ages (a) 1-day vs. 28 days, (b) 7 days vs. 28 days 


\section{Conclusions}

In this study, a mixing procedure for Ultra-lightweight EPS concrete was developed and predictive compressive strength models function of concrete mixture and density were formulated. An experimental program was developed to implement the mixing procedure and to calibrate and evaluate the accuracy of the strength models. This study revealed the following main conclusions:

- The proposed mixing procedure was successfully implemented and all 30 mixtures has shown homogeneity, stability, and no segregation.

- The proposed compressive strength models provide a good fit to the experimental data. The standard error for both models is less than $0.3 \mathrm{MPa}$ and the corresponding correlation coefficient is greater than 0.93. These models can be utilized in the design of concrete mixtures to meet specific strength requirements as a priority and ensure quality control before concrete is cast.

- In order to ensure quality control before concrete is cast, a link between the plastic density of fresh concrete and the compressive strength of hardened concrete was established. The corresponding correlation coefficient was 0.86 .

- The effects of concrete age on strength development were studied and the 28-day compressive strength was related to strengths at early ages. Results reveal that EPS concrete develops around $48 \%$ of its 28 -day strength in 1-day, and $83 \%$ in 7 days. The corresponding correlation coefficients were 0.83 and 0.89 for the 1-day strength and 7-day strength, respectively. This is important to accommodate tight construction schedules.

\section{Acknowledgements}

This work was supported by the American University of Ras Al Khaimah and Concrete Technology LLC. The author would like to thank Concrete Technology LLC for providing the resources to successfully conduct the experimental part of the paper. The author would like to thank the American University of Ras Al Khaimah for providing additional resources and time that helped shape up the development of the analysis and writing of the paper

\section{RERERENCES}

[1] B.A. Herki, J.M. Khatib. Valorisation of waste expanded polystyrene in concrete using a novel recycling technique, European Journal of Environmental and Civil Engineering, Vol. 21, No. 11, 1-19, 2016.

[2] J.M. Khatib, B.A. Herki, A. Elkordi. Characteristics of concrete containing EPS, Woodhead Publishing Series in Civil and Structural Engineering, Elsevier Ltd, 137-165, 2019.

[3] M.A.R. Bhutta, Y. Ohama, K. Tsuruta, Strength properties of polymer mortar panels using methyl methacrylate solution of waste expanded polystyrene as binder, Construction and Building Materials, Elsevier Ltd, Vol. 25, No. 2, 779-784, 2011.

[4] D.J. Cook. Expanded polystyrene beads as lightweight aggregate for concrete, Precast Concrete, Vol. 4, 691-693, 1973.

[5] C. Bagon, S. Frondistou. Marine floating concrete made with polystyrene beads, Magazine of Concrete Research, Vol. 28, 225-229, 1976.

[6] D.J. Cook. Expanded polystyrene concrete, Concrete Technology and Design, New Concrete Materials, Vol. 1, London: Surrey University Press, 41-69, 1983.

[7] S.H. Perry, P.H. Bischoff, K. Yamura. Mix details and material behaviour of polystyrene aggregate concrete, Magazine of Concrete Research, Vol. 43, 71-76, 1991.

[8] R.S. Ravindrarajah, A.J. Tuck. Properties of hardened concrete containing treated expanded polystyrene beads, Cement Concrete Composites, Vol. 16, 273-277, 1994.

[9] B. Chen, J. Liu. Properties of lightweight expanded polystyrene concrete reinforced with steel fiber, Cement and Concrete Research, Vol. 34, No. 7, 1259-1263, 2004.

[10] A. Kan, R. Demirboğa. Effect of cement and EPS beads ratios on compressive strength and density of lightweight concrete, Indian Journal of Engineering \& Materials Sciences, Vol. 14, 158-162, 2007.

[11] A. Kan, R. Demirboğa. A novel material for lightweight concrete production, Cement and Concrete Composites, Vol 31, No. 7, 489-495, 2009.

[12] ACI 234: Guide for the use of silica fume in concrete, ACI 234R-96, American Concrete Institute, Farmington Hills, Michigan, 2000

[13] R.S. Ravindrarajah, J. Collins. Temperature development in concrete with EPS beads, paper presented at AUSTCERM 98, Melbourne, Australia, 1998.

[14] K.G. Babu, D. S. Babu. Behaviour of lightweight expanded polystyrene concrete containing silica fume, Cement and Concrete Research, Vol. 33, 755-762, 2003.

[15] B. Sabaa B, R.S. Ravindrarajah. Workability assessment for polystyrene aggregate concrete, paper presented at $7^{\text {th }}$ Quality Control Congress, Montevideo, Uruguay, 1999.

[16] D.S. Babu, K.G. Babu, W. Tiong-Huan. Effect of polystyrene aggregate size on strength and moisture migration characteristics of lightweight concrete, Cement and Concrete Composites, Vol. 28, No. 6, 520-527, 2006.

[17] K. Miled, K. Sab, R. Le Roy. Particle size effect on EPS lightweight concrete compressive strength: experimental investigation and modelling. Mechanics of Materials, Vol. 39, No. 3, 222-240, 2007.

[18] ASTM C 138-17: Standard test method for density (unit weight), yield, and air content (gravimetric) of concrete, 
ASTM, West Conshohocken, PA, 2017.

[19] ASTM C143-15: Standard test method for slump of hydraulic-cement concrete, ASTM, West Conshohocken, PA, 2015.

[20] ASTM C567-19: Standard test method for density of structural lightweight concrete, ASTM, West Conshohocken, PA, 2019.

[21] D. C. Montgomery, G. C. Runger. Applied Statistics and Probability for Engineers, 3rd edn. Wiley, New York, USA, 2003. 